\title{
Solanum betaceum in vitro seed germination and seedling development in response to pregerminative treatments
}

K. S. Salazar-Vega ${ }^{1}$, I. Vaca ${ }^{1}$

DOI. 10.21931/RB/2021.06.01.12

Abstract: Germination and seedling development are critical stages in the life cycle of plants. Insufficient seedling emergence and inadequate establishment of woody plants are significant constraints in producing crops such as tamarillo. The application of pregerminative protocols improves the germination percentage, reduces the seedling emergence time, and improves several species in vitro. The present study was conducted to contrast three pregerminative treatments on Solanum betaceum seeds. When evaluating the pregerminative treatments, treatment T3 (imbibition for 24 hours) obtained the best results, showing an average of 21.62 days to germination, $73 \%$ germinated seeds and 2.31 leaves per explant.

Key words: Tamarillo, imbibition, agriculture, biotechnology, plant tissue culture.

\section{Introduction}

Solanum betaceum or tamarillo is a plant species from the Andean territory. This species is mainly grown due to its high nutritional value of edible fruits. Commercial production of plants using micropropagation techniques has several advantages over traditional propagation methods; in addition to being a rapid propagation process, it can lead to pathogen-free plants' production.

Pregerminative treatments can be applied to seed explants before or after a disinfection protocol has been developed. The objective of pregerminative treatments is to improve the germination rate while ensuring the successful development of the seedlings, playing an essential role as the first step in crop cultivation. The rigid structure of seed coats may be the reason for seed dormancy depending on the species, making it difficult to absorb water during germination; physical, mechanical, or chemical scarification treatments help resolve dormancy conditions in the seeds. The use of procedures to end the tegument's dormancy causes a better response in the time, and a higher percentage of germination, one of the common strategies is to hydrate the seeds for $24 \mathrm{~h}$ at room temperature.

The scarification procedure's efficiency depends on the technician's skill and practice; if the scarification is too deep, it may damage the embryonic axis, and if it is too shallow, it may not be enough to overcome the mechanical barriers that block seed germination.

Pregerminative treatments induced a particular physiological state in the seeds and had become a promising strategy to improve a plant's behavior in the field; there is great interest for farmers and seed companies to find suitable affordable pregerminative treatments, but also to precisely identify the improved agronomic properties as a result of their application in crops.

\section{Methods}

First, the seeds were soaked in $1.33 \% \mathrm{v} / \mathrm{v}$ iodine for $15 \mathrm{mi}$ nutes, followed by 3 washes with sterile distilled water. Then they were immersed in sodium hypochlorite at $1.5 \% \mathrm{v} / \mathrm{v}$ for 10 minutes, 5 washes were carried out with sterile distilled water. The disinfection protocol was then performed in a laminar flow cabinet, disinfected in advance with $70 \%$ alcohol, and exposed to ultraviolet light for $15 \mathrm{~min}$, adjacent to the instruments to be handled. Basal medium MS (MS519) was prepared with a $50 \%$ salt concentration, enriched with $20 \mathrm{~g} / \mathrm{L}$ of sucrose, $6 \mathrm{~g} / \mathrm{L}$ of Phyto Agar, and 50 ppm of citric acid. The medium's pH was adjusted to 5.8 , and it was sterilized by autoclaving at $121^{\circ} \mathrm{C}$ for 15 minutes. The experimental unit was set as $2 \times 15 \mathrm{~cm}$ borosilicate glass screw cap culture tubes containing $15 \mathrm{~mL}$ of culture medium; 2 seeds were placed per tube. The treatments are described in table 1 [NSV4].

\section{Results and Discussion}

\section{Germination}

Treatment T3 showed the lowest number of days to germination with an average of 21.62 days, besides it reached an average of $73 \%$ germination, this response is attributed to the hydration time for 24 hours (Figure 1); it is consistent with several authors who report an increase in germination tanks

\begin{tabular}{|c|l|}
\hline TREATMENT & DESCRIPTION \\
\hline T1 & $\begin{array}{l}\text { 10 vol. Hydrogen peroxide, during 5 min; } 48 \mathrm{~h} \\
\text { hydropriming and changing of water at 24 h }\end{array}$ \\
\hline T2 & Scarification and hydro priming during $24 \mathrm{~h}$ \\
\hline T3 & Hydropriming during $24 \mathrm{~h}$ \\
\hline T0 & Control treatment \\
\hline
\end{tabular}

Table 1. Pregerminative treatments applied to Solanum betaceum seeds. 


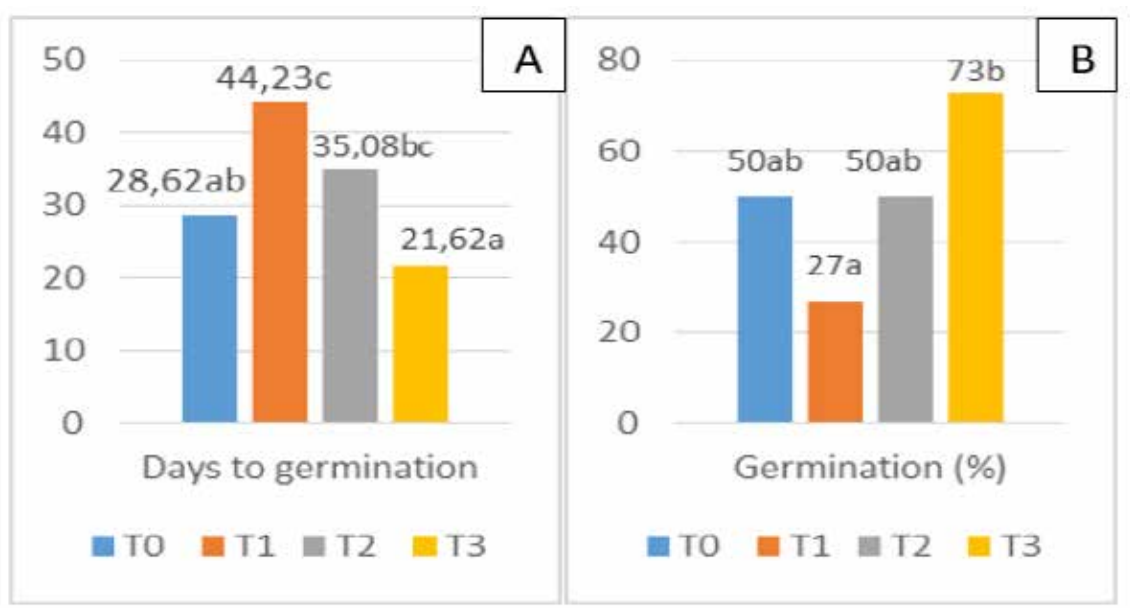

Figure 1. Effects of pregerminative treatments on Solanum betaceum seeds in vitro. A. Days to germination B. Germination percentage.

to pregerminative treatments that involved hydration of the seeds $^{1-3}$. In previous articles, it is pointed out that during the seed's imbibition, the meristematic activity is limited; however, preparation for cell division already occurs ${ }^{4}$. Hydro priming activates metabolic processes such as hydrolysis, the activation of enzymes, and the breaking of dormancy in seeds, favoring the expansion of the embryo and significantly decreasing the time of emergence of the radicle ${ }^{5}$. Treatment T3 shows a higher germination percentage than those presented by $\mathrm{Mu}$ rillo-Gómez, Hoyos, \& Chavarriaga ${ }^{6}$, who reported $57.5 \%$ of Solanum betaceum seeds germinated; these were scarified and seeded in MS medium with 3 ppm of BAP. This induced improvement in the germination process is based on hydro priming on the activation of DNA repairing mechanisms, synchronization of the cell cycle in the G2 phase, and cell division prepping ${ }^{7}$.

Although scarification was expected to optimize the germination response by facilitating water absorption, T2 did not show a better response than the control treatment, producing only $50 \%$ of germination and 35.08 days to germination (Figure 1B). This fact agrees with authors who state that scarification can damage the embryo, abnormal seedlings, and dead seeds ${ }^{8}$. Furthermore, in most of the species studied, scarification was not the treatment that achieved $100 \%$ germination, requiring other pregerminative procedures, or the combination with other factors that break dormancy, such as lighting, refrigeration, thermal shock, among others ${ }^{9}$.
T1 showed the lowest germination percentage; this characteristic could be attributed to the amount of imbibition time, which was higher compared to the other treatments; Trigiano \& Gray ${ }^{10}$, point out that an excess of the amount of water available in the imbibition can negatively affect the suppression of dormancy speed in germinated seeds in vitro; agreeing with Trimble ${ }^{11}$. It indicates that imbibition of the seed initiates germination, in which water and oxygen are necessary to keep the process going. However, an excess of water around the seed can cause an insufficient oxygen supply for the cells that were growing and dividing rapidly, which would stop the germination process.

\section{Number and color of leaves}

Treatment T3 showed the highest number of leaves, with 2,31 leaves per explant, and the best color, with an average of 2,65, which means that the leaves presented a dark green color (Figure 2). The highest number of leaves $(2,31)$ showed by $\mathrm{T} 3$ can be attributed to this treatment's advantage due to the early germination, which handed an advantage in metabolic and morphogenetic mechanisms to the Vitro plants. Early germination has been considered a characteristic to be avoided by some authors ${ }^{12}$; however, research works suggest that plants produced by induced early germination were not affected morphologically, and the germination time was favorably reduced ${ }^{13}$.

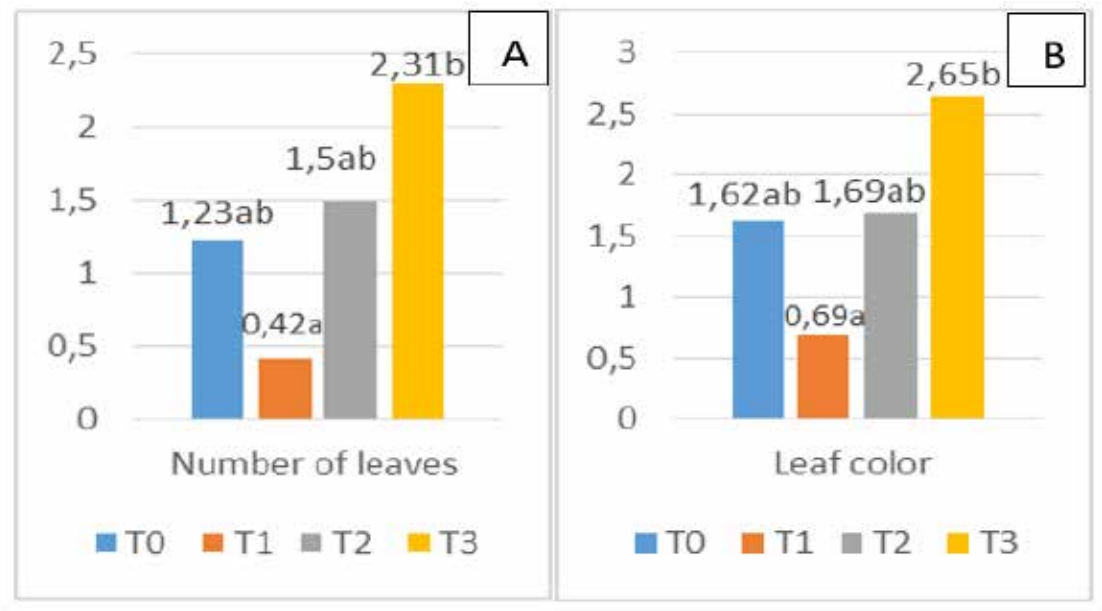

Figure 2. Effects of pregerminative treatments on Solanum betaceum seedlings in vitro. A. Number of leaves. B. Leaf in color. 
A deep green color is considered a sign of health in Solanum betaceum plants. The color of the leaves of a plant is an indicator of health and vigor, as a deeper green indicates a higher concentration of chlorophyll, which allows higher efficiency in the transformation of solar energy into glucose ${ }^{14}$. Casierra-Posada, Peña-Olmos, \& Ulrichs ${ }^{15}$, also conclude an essential link between coloration and the chlorophyll index. Due to insufficient chlorophyll content, a low-intensity green color in the leaf blade can signify stress or senescence in plants ${ }^{16}$. Besides that, the leaf's color is one of the main parameters for fruit producers, playing a crucial role in the choice, preference, and acceptability of the plants ${ }^{17}$.

\section{Bacterial contamination}

T1 was the only treatment that displayed bacterial contamination (42\%) (Figure 3A), this characteristic could be due to an exogenous microbial source that could have come into contact with the seeds when the changing of distilled water after
24 hours occurred (this process was not performed in the rest of the treatments); Farooq, Wahid, \& Siddique ${ }^{18}$, consider the imbibition process with leachate washing as a possible source of contamination. Likewise, $\mathrm{Ma}^{19}$ indicates that storing seeds that keep their coverage under hydration generally maintains high microbial viability.

\section{Conclusions}

The best pregerminative treatment was T3 (imbibition for 24 hours), applied on Solanum betaceum seeds, showing an average of 21.62 days to germination, $73 \%$ germinated seeds, and 2.31 leaves with a deep green color $(2.65 / 5)$.

\section{Acknowledgments}

To Jael Álvarez, Marco Pozo and Sebastián Pillalaza, for their great assistance in laboratory tasks.

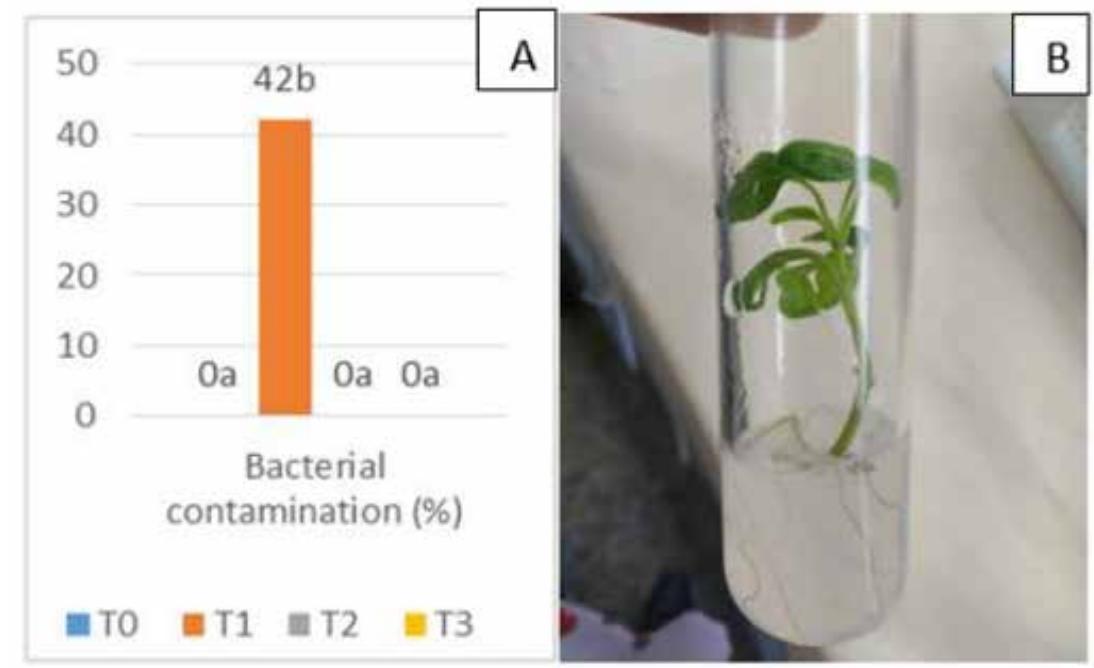

Figure 3. Effects of pregerminative treatments on Solanum betaceum in vitro. A. Bacterial contamination percentage. B. 45 days seedling.

\section{Bibliographic references}

1. Fallah S, Malekzadeh S, Pessarakli M. Seed priming improves seedling emergence and reduces oxidative stress in Nigella sativa under soil moisture stress. J Plant Nutr. 2018;41(1):29-40. doi:10 .1080/01904167.2017.1381719

2. Górnik K, Lahuta LB. Application of phytohormones during seed hydropriming and heat shock treatment on sunflower (Helianthus annuus L.) chilling resistance and changes in soluble carbohydrates. Acta Physiol Plant. 2017;39(5). doi:10.1007/s11738017-2413-x

3. Noorhosseini SA, Jokar NK, Damalas CA. Improving Seed Germination and Early Growth of Garden Cress (Lepidium sativum) and Basil (Ocimum basilicum) with Hydro-priming. J Plant Growth Regul. 2018;37(1):323-334. doi:10.1007/s00344-017-9728-0

4. Lutts S, Benincasa P, Wojtyla L, et al. Seed Priming: New Comprehensive Approaches for an Old Empirical Technique. In: New Challenges in Seed Biology - Basic and Translational Research Driving Seed Technology. InTech; 2016. doi:10.5772/64420

5. Ogbuehi HC, Madukwe DK, Ashilonu P. ASSESSMENT OF HYDRO PRIMING OF SEEDS ON PERFORMANCE OF MORPHOLOGICAL INDICES OF BAMBARA GROUNDNUT (VIGNA SUBTERRENEA LINN.) LANDRACE. Glob J Biol Agric Heal Sci. 2013;2(2):17-22.

6. Bewley JD, Bradford KJ, Hilhorst HWM, Nonogaki H. Seeds: Physiology of Development, Germination and Dormancy, 3rd Edition. Vol 9781461446.; 2013. doi:10.1007/978-1-4614-4693-4
7. Murillo-Gómez PA, Hoyos R, Chavarriaga P. Organogénesis in-vitro usando tres tipos de tejidos de tomate de árbol [Solanum betaceum (Cav.)]. Agron Colomb. 2017;35(1):5-11. doi:10.15446/ agron.colomb.v35n1.61330

8. Chaodumrikul S, Kaewsorn P, Chulaka P, Chanprasert W. Breaking seed dormancy in smooth loofah (Luffa cylindrica (L.) M. Roem.) using scarification and dry heat treatment. Agric Nat Resour. 2016;50(2):85-88. doi:10.1016/j.anres.2015.09.003

9. Bradbeer JW. Seed Dormancy and Germination. First. (Springer Science \& Business Media, ed.).; 2013. doi:10.1007/978-94-011-6574-7_8

10. Trigiano RN, Gray DJ. Plant Tissue Culture, Development, and Biotechnology. 1st Editio. (Trigiano RN, Gray DJ, eds.). Boca Raton: CRC Press; 2016. doi:10.1201/9781439896143

11. Trimble S. Encyclopedia of Water Science, Second Edition (Print Version):; 2007. doi:10.1201/noe0849396274

12. Hugo Cota-Sánchez J. Precocious Germination (Vivipary) in Tomato: A Link to Economic Loss? Proc Natl Acad Sci India Sect B Biol Sci. 2018;88(4):1443-1451. doi:10.1007/s40011-017-0878-4

13. Flores HE, Sgrignoli PJ. In vitro culture and precocious germination of Taxus embryos. Vitr Cell Dev Biol - Plant. 1991;27(3):139142. doi:10.1007/BF02632197

14.Zhang R, Ren Z, Sun J, Tang W, Ning D, Qian Y. Method for monitoring the cotton plant vigor based on the WSN technology. Comput Electron Agric. 2017;133:68-79. doi:10.1016/j.compag.2016.12.009 
15. Casierra Posada F, Peña Olmos J, Ulrichs C. Crecimiento y eficiencia fotoquímica del fotosistema II en plantas de fresa (Fragaria sp.) Afectadas por la calidad de la luz: implicaciones agronómicas. Rev UDCA Actual Divulg Científica. 2011;14(2). doi:10.31910/ rudca.v14.n2.2011.774

16. Shankar A, Gupta RK, Singh B. Establishing indicator leaf and its threshold values for need based nitrogen management using chlorophyll meter and leaf color chart in Bt cotton. J Plant Nutr. 2019;42(2):186-201. doi:10.1080/01904167.2018.1551492

17. Sarker U, Oba S. Augmentation of leaf color parameters, pigments, vitamins, phenolic acids, flavonoids and antioxidant activity in selected Amaranthus tricolor under salinity stress. Sci Rep. 2018:8(1):12349. doi:10.1038/s41598-018-30897-6

18. Farooq M, Wahid A, Siddique KHM. Micronutrient application through seed treatments - a review. J Soil Sci Plant Nutr. 2012;12(1):125-142. doi:10.4067/S0718-95162012000100011

19. Ma Y. Seed coating with beneficial microorganisms for precision agriculture. Biotechnol Adv. 2019;37(7):107423. doi:10.1016/j.biotechadv.2019.107423

Received: 18 December 2020

Accepted: 10 January 2021 